\title{
RNA-Seq derived identification of differential transcription in the chrysanthemum leaf following inoculation with Alternaria tenuissima
}

\author{
Huiyun $\mathrm{Li}^{1,2}$, Sumei Chen ${ }^{1}$, Aiping Song ${ }^{1}$, Haibin Wang ${ }^{1}$, Weimin Fang ${ }^{1}$, Zhiyong Guan ${ }^{1}$, Jiafu Jiang ${ }^{1 *}$
} and Fadi Chen ${ }^{1,2^{*}}$

\begin{abstract}
Background: A major production constraint on the important ornamental species chrysanthemum is black spot which is caused by the necrotrophic fungus Alternaria tenuissima. The molecular basis of host resistance to $A$. tenuissima has not been studied as yet in any detail. Here, high throughput sequencing was taken to characterize the transcriptomic response of the chrysanthemum leaf to A. tenuissima inoculation.

Results: The transcriptomic data was acquired using RNA-Seq technology, based on the Illumina HiSeq ${ }^{\text {TM }} 2000$ platform. Four different libraries derived from two sets of leaves harvested from either inoculated or mock-inoculated plants were characterized. Over seven million clean reads were generated from each library, each corresponding to a coverage of $>350,000 \mathrm{nt}$. About $70 \%$ of the reads could be mapped to a set of chrysanthemum unigenes. Read frequency was used as a measure of transcript abundance and therefore as an identifier of differential transcription in the four libraries. The differentially transcribed genes identified were involved in photosynthesis, pathogen recognition, reactive oxygen species generation, cell wall modification and phytohormone signalling; in addition, a number of varied transcription factors were identified. A selection of 23 of the genes was transcription-profiled using quantitative RT-PCR to validate the RNA-Seq output.

Conclusions: A substantial body of chrysanthemum transcriptomic sequence was generated, which led to a number of insights into the molecular basis of the host response to A. tenuissima infection. Although most of the differentially transcribed genes were up-regulated by the presence of the pathogen, those involved in photosynthesis were down-regulated.
\end{abstract}

Keywords: Ornamental plant, Alternaria tenuissima, RNA-Seq, Cell wall modification genes

\section{Background}

Chrysanthemum (Chrysanthemum morifolium Ramat.) is the second most commercially valuable ornamental species after rose $[1,2]$. A serious production constraint is represented by black spot disease (causative pathogen the necrotrophic fungus Alternaria tenuissima (Fr.) Wiltsh) [3]. The disease is most damaging during humid, warm conditions, which makes it a year-round problem for greenhousebased production $[3,4]$. Severe infections damage the commercial value of the plant, as they cause leaf necrosis, and

\footnotetext{
* Correspondence: jiangjiafu@njau.edu.cn; chenfd@njau.edu.cn ${ }^{1}$ College of Horticulture, Nanjing Agricultural University, Nanjing 210095, China 2Jiangsu Province Engineering Lab for Modern Facility Agriculture Technology and Equipment, Nanjing 210095, China
}

reduce the quantity and quality of the flowers [5]. Little is known regarding the chrysanthemum/black spot hostpathogen interaction. However, in the host-pathogen system involving the model species Arabidopsis thaliana and the related pathogen $A$. brassicicola, the pathogenesisrelated protein PR4 is significantly up-regulated [6]. In the tomato/A. alternata system, the ethylene (ET), jasmonate (JA) and salicylic acid (SA) signalling pathways are all activated as part of the host response [7], while the response of mint to A. alternata infection features many proteins related to stress and defence [8]. Finally, Egusa et al. (2009) [9] have shown that the transcription of the genes PGIP (polygalacturonase inhibiting protein) and $P P O$ (polyphenol oxidase) is induced in the leaf of the Japanese pear 
when challenged by $A$. alternata. Plant defence responses are first activated in the organs located at the site of infection but are then extended to the uninfected systemic (distal) organs, activating a systemic acquired resistance (SAR) which is effective against a broad spectrum of pathogens in the whole plant [10-12]. However, limited studies have examined the induction of SAR in chrysanthemum/black spot host-pathogen interaction, so far. In the present study, the systemic responses are expected by surveying gene expression profiles in the noninfected (systemic) leaves.

RNA-Seq technology has been developed to enable the simultaneous sequencing of very large numbers of short reads, and in so doing has revolutionized the qualitative and quantitative analysis of the transcriptome [13-16]. When applied to cotton infected with a wilt pathogen, of the $>32,000$ genes identified by mapping the reads to a genomic sequence assembly, over 3,000 were found to be upor down-regulated as part of the defence response [16]. Similarly, an analysis of the banana-Fusarium oxysporum interaction successfully demonstrated the up-regulation of genes involved in hormone synthesis, pathogenesis-related genes, transcription factors and signalling/regulatory genes [17]. Finally, the lettuce-Botrytis cinerea interaction has been shown to feature the induction of genes involved in the phenylpropanoid pathway and in terpenoid synthesis, as well as a global down-regulation of genes responsible for photosynthesis [18].

In present study, we aimed to 1) elucidate the localized responses to the infections on the inoculated site by comparing libraries generated from mock-inoculated and inoculated leaves; 2) to describe the systemic response by comparing libraries generated from neighbouring leaves from mock-inoculated and inoculated leaves. The present study reports the outcome of a RNA-Seq based analysis of the chrysanthemum- $A$. tenuissima interaction. The experiment has yielded information regarding the identity of the genes which are either up- or down-regulated as part of the defence response. The majority of the differentially transcribed (DT) genes were involved in either pathogen recognition, reactive oxygen species detoxification, cell wall modification or phytohormone signalling, but also a range of transcription factors, belonging to various families were identified. Validation of the RNA-Seq data was provided by subjecting a set of 23 of the DT genes to quantitative RT-PCR (qPCR).

\section{Results}

\section{Analysis of RNA-Seq libraries}

The major characteristics of the four libraries (Figure 1) are summarized in Table 1 and Additional file 1: Figure S1. The number of raw reads per library ranged from $\sim 7.2$ to 7.6 million, and the total number of base pairs sequenced from 352,864,582 to 370,177,360 (Table 1) (Accession No. for library A SRS464569; Accession No. for library

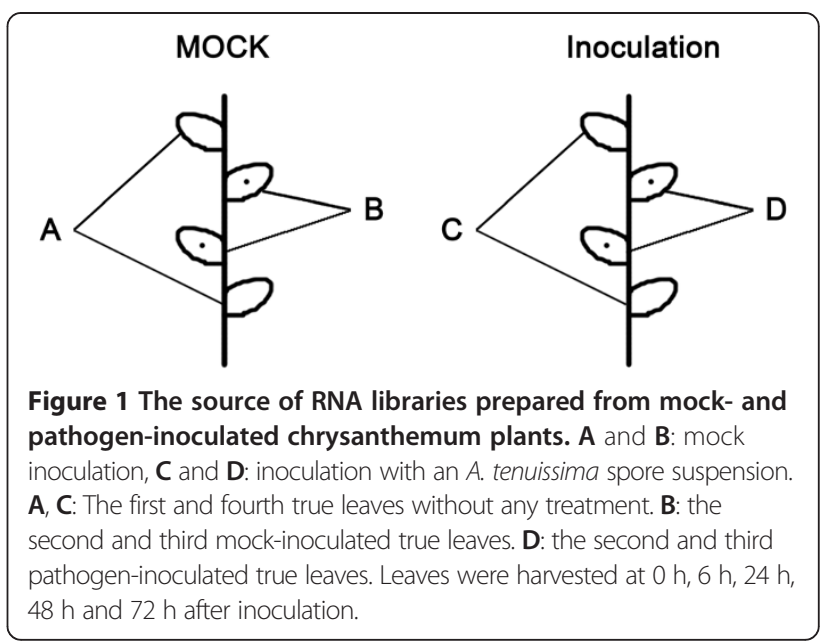

B SRS480632; Accession No. for library C SRS480633; Accession No. for library D SRS480635). After removal of reads including adaptor sequence, reads in which $>10 \%$ of the bases were uncertain, a total of, respectively $7,524,234,7,248,778,7,201,318$ and 7,554,640 clean reads were obtained, corresponding to $368,687,466,355,190,122$, $352,864,582$ and $370,177,360$ base pairs (Table 1). The proportion of clean reads was $>99.30 \%$ in each library (Additional file 1: Figure S1).

\section{Read mapping}

A reference gene database [Raw sequence data were deposited in the NCBI Sequence Read Archive database (http://trace.ncbi.nlm.nih.gov/Traces/sra_sub/sub.cgi?) under accession number SRP029991] which included all known Chrysanthemum morifolium unigene sequences was used to map the RNA-Seq reads. Based on the chosen criteria, $69.75 \%$ of the clean reads recognized sequences in this database (Table 1). On a per library basis, the proportions of the clean reads uniquely mapped to the database were, respectively, $46.81 \%, 45.82 \%, 46.14 \%$ and $44.56 \%$. In addition, the proportion of the clean reads from library D uniquely mapped to the publicly available A.tenuissima database was $0.02 \%$. The number of genes identified increased with the number of reads, but above 6,000,000 reads no further genes were detected, implying full saturation of the transcriptome (Figure 2).

\section{GO classification of DT genes}

Of the 217 genes classified as DT genes in the contrast between library A (leaf 1 and 4 of plants mock-inoculated on leaf 2 and 3) and B (mock-treated leaf 2 and 3), 106 could be assigned a GO classification; the equivalent number for the A vs C (leaf 1 and 4 of plants inoculated by the pathogen on leaf 2 and 3) contrast was 418 out of 659 , for the B vs D (pathogen-infected leaf 2 and 3) contrast 1,057 out of 1,705 , and for the C vs D contrast 294 out of 494 
Table 1 Summary of read mapping

\begin{tabular}{cccccccccc}
\hline Sample ID & Total reads & $\begin{array}{c}\text { Total } \\
\text { basepairs }\end{array}$ & $\begin{array}{c}\text { Total mapped } \\
\text { reads }\end{array}$ & Perfect match & $\begin{array}{c}<=2 \text { bp } \\
\text { mismatch }\end{array}$ & $\begin{array}{c}\text { Unique match } \\
\text { Multi-position } \\
\text { match }\end{array}$ & $\begin{array}{c}\text { Total unmapped } \\
\text { reads }\end{array}$ \\
\hline A & 7524234 & 368687466 & 5429990 & 3412870 & 2017120 & 3522413 & 1907577 & 2094244 \\
& $(100.00 \%)$ & $(100.00 \%)$ & $(72.17 \%)$ & $(45.36 \%)$ & $(26.81 \%)$ & $(46.81 \%)$ & $(25.35 \%)$ & $(27.83 \%)$ \\
B & 7248778 & 355190122 & 5069400 & 3184769 & 1884631 & 3321526 & 1747874 & 2179378 \\
& $(100.00 \%)$ & $(100.00 \%)$ & $(69.93 \%)$ & $(43.94 \%)$ & $(26.00 \%)$ & $(45.82 \%)$ & $(24.11 \%)$ & $(30.07 \%)$ \\
C & 7201318 & 352864582 & 5033405 & 3149786 & 1883619 & 3322965 & 1710440 & 2167913 \\
& $(100.00 \%)$ & $(100.00 \%)$ & $(69.90 \%)$ & $(43.74 \%)$ & $(26.16 \%)$ & $(46.14 \%)$ & $(23.75 \%)$ & $(30.10 \%)$ \\
D & 7554640 & 370177360 & 5060651 & 3142621 & 1918030 & 3366700 & 1693951 & 2493989 \\
& $(100.00 \%)$ & $(100.00 \%)$ & $(66.99 \%)$ & $(41.60 \%)$ & $(25.39 \%)$ & $(44.56 \%)$ & $(22.42 \%)$ & $(33.01 \%)$ \\
\hline
\end{tabular}

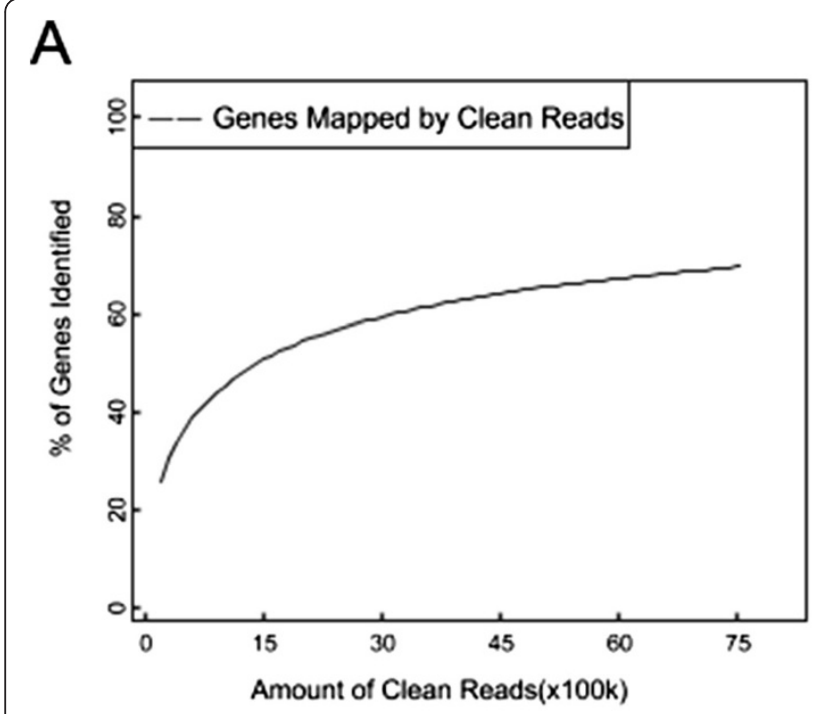

B

C
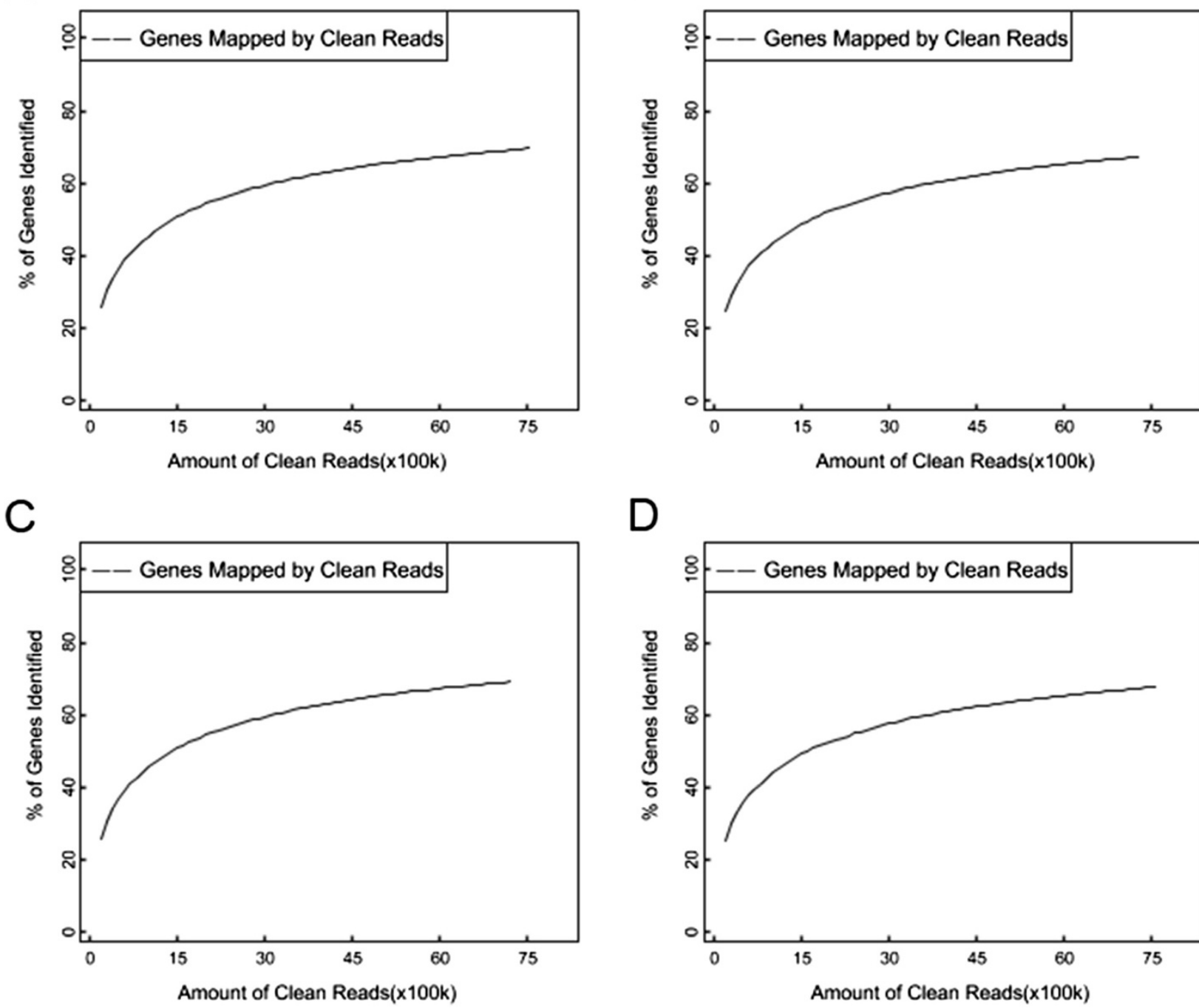

D

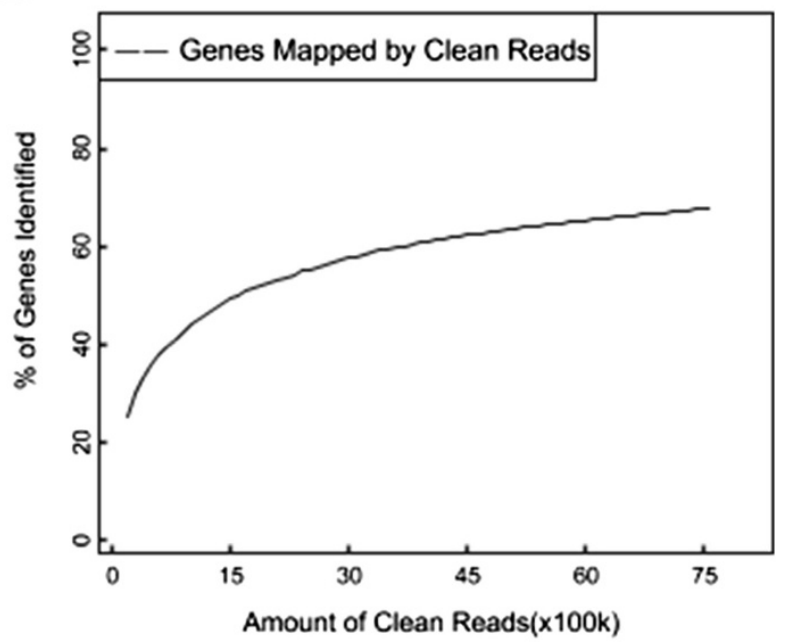

Figure 2 Sequencing saturation analysis of each library. Sequencing saturation in the four libraries of $\mathbf{A}, \mathbf{B}, \mathbf{C}$ and $\mathbf{D}$. The number of different genes detected rose as the read number was increased. 
(Additional file 2: Table S1, Additional file 3: Table S2, Additional file 4: Table S3 and Additional file 5: Table S4, Additional file 6: Table S5, Additional file 7: Table S6, Additional file 8: Table S7 and Additional file 9: Table S8). Furthermore, of the 659 genes classified as DT genes in the contrast between library A and C (A vs C), 469 (71.2\%) behaved similarly between $\mathrm{A} v s \mathrm{C}$ and $\mathrm{B} v s \mathrm{D}$; the equivalent number for the B vs D contrast was 469 out of 1705 (27.5\%) (Additional file 7: Table S6 and Additional file 8: Table S7). For the A vs B contrast, seven genes were categorized as "cellular component", six as "molecular function" and 14 as "biological process"; the respective distributions in $\mathrm{A} v s \mathrm{C}, \mathrm{B}$ vs $\mathrm{D}$ and $\mathrm{C} v s \mathrm{D}$ were ten, ten and 20, nine, 11 and 20, and nine, nine and 18 (Figure 3 ). The frequency of DT genes was highest in the contrast B vs D. The commonest molecular functions of the DT genes in this contrast were binding and catalytic activity; in terms of cellular component, most were associated with cells, cell parts, macromolecular complexes, membranes, membrane parts, organelles and organelle parts; finally, in terms of biological process, the majority were associated with cellular processes, metabolic processes and the response to stimulus (Figure 3). Signalling responses to or mediated by JA, SA and ET were well represented, particularly those active in JA-mediated signalling. Some transcription factors and cell wall modification genes were also differentially transcribed, as were genes involved in secondary metabolism (phenylpropanoid pathway and terpenoid synthesis). Among the biological processes well represented among the down-regulated genes were those involved in photosynthesis. In the contrast between B and D, a small number of up-regulated genes belonged to the categories 'cell killing', 'positive regulation of biological process', 'membrane-enclosed lumen' and 'receptor activity'. A higher number of genes identified in this contrast were associated with 'response to stimulus' and 'signalling' than in the contrasts $\mathrm{A} v s \mathrm{~B}, \mathrm{~A}$ vs $\mathrm{C}$ and $\mathrm{C}$ vs $\mathrm{D}$ (Figure 3).

\section{Changes in transcription level}

The distribution of unigene coverage in each sample was analysed as a way of evaluating the quality of the RNASeq dataset (Figure 4). The term "gene coverage" reflects the proportion of the full gene sequence represented by RNA-Seq reads. For most of the unigenes, gene coverage was $>50 \%$. The transcription level of each unigene (Additional file 10: Table S9) was derived from the number of relevant reads recovered following Mortazavi et al. (2008) [19]. DT genes (Additional file 6: Table S5, Additional file 7: Table S6, Additional file 8: Table S7, Additional file 9: Table S8) were identified using an algorithm developed by Audic et al. (1997) [20]. Between A and B, 20 genes were up- and 197 down-regulated, between $A$ and $C$, the totals were 562 and 97, respectively, between B and D, 1,181 and 524, respectively and C and D, 245 and 249, respectively (Figure 5).

\section{Transcription factors, cell wall modification genes and} genes involved in JA and SA signalling were all regulated by $A$. tenuissima inoculation

The transcription data indicated that infection by $A$. tenuissima regulated a number of transcription factors and genes associated with pathogenesis and JA and SA signalling. Three members of the GRAS-type transcription factor family were more abundantly transcribed in the inoculated than in the mock-inoculated leaves. When qPCR was performed on a selection of the 23 of the DT genes to validate the conclusions drawn from the RNASeq analysis, all the genes behaved as predicted. Most of the genes examined (the exception was the MYB transcription factor CL9570) were induced after A. tenuissima inoculation (Table 2). The qPCR analysis suggested that genes involved in cell wall modification, JA and SA signalling and transcription factors comprised a network of interactions, providing the host with a capacity to fine-tune its disease response.

\section{Discussion}

\section{Global patterns of transcription in response to infection} by $A$. tenuissima

The chrysanthemum genome is polyploid and large, so has not as yet benefited from comprehensive and integrated genomic and transcriptomic sequence analysis. The molecular basis of its defence response against pathogen infection is currently poorly understood, but the advent of high-throughput sequencing technology now allows an unprecedented opportunity to explore it. About 70\% of the reads in each of the four RNA-Seq libraries were mappable back to known transcripts (Table 1), a proportion which is somewhat lower than achieved in the lettuce/ $B$. cinerea system [18], probably reflecting the more comprehensive status of the lettuce transcriptome. The $30 \%$ of reads which were not mappable are presumably associated with as yet unidentified transcripts [16]. The validation through qPCR of the transcripts identified as regulated by A. tenuissima infection showed that the RNA-Seq method is well suited for the analysis of transcription induced as part of the defence response in chrysanthemum (Table 2). In all, $659 \mathrm{DT}$ genes were identified in the $\mathrm{A}$ vs $\mathrm{C}$ contrast and 1,705 in B vs D (Figure 5, Tables S7, S8). A comparison with the outcomes of the lettuce/B. cinerea and $A$. thaliana/B. cinerea interactions $[18,21,22]$ showed that only two genes were up-regulated in all three systems, namely Lsa004290.1, At1g74360 and Unigene7965_All (encoding an LRR protein kinase) and Lsa016859.1, At4g17 500 and Unigene17395_All (ERF1). During the early phase of both the lettuce/B. cinerea and the $A$. thaliana/B. cinerea interactions, genes in the ET pathway are heavily involved 


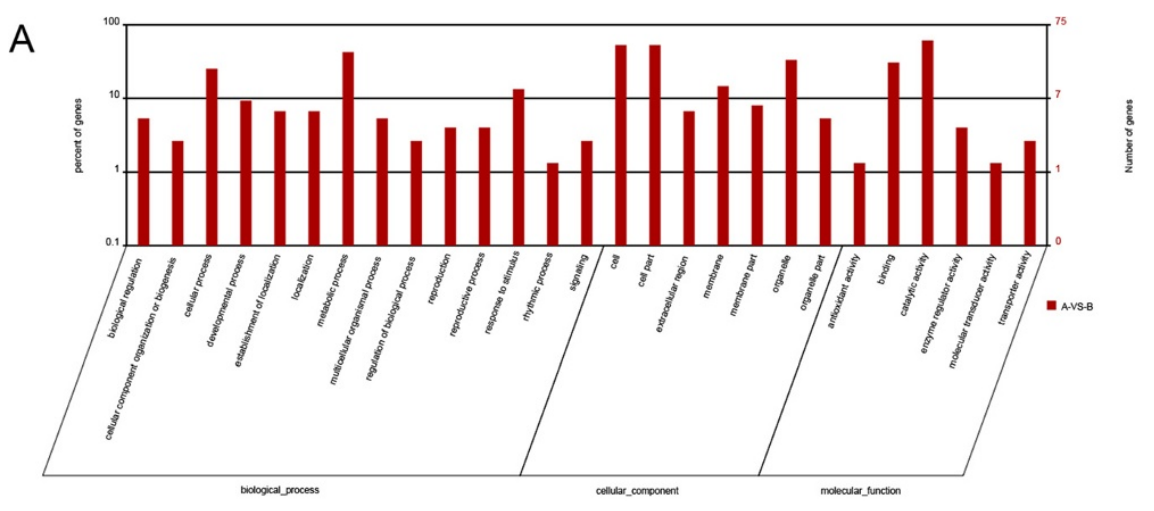

B

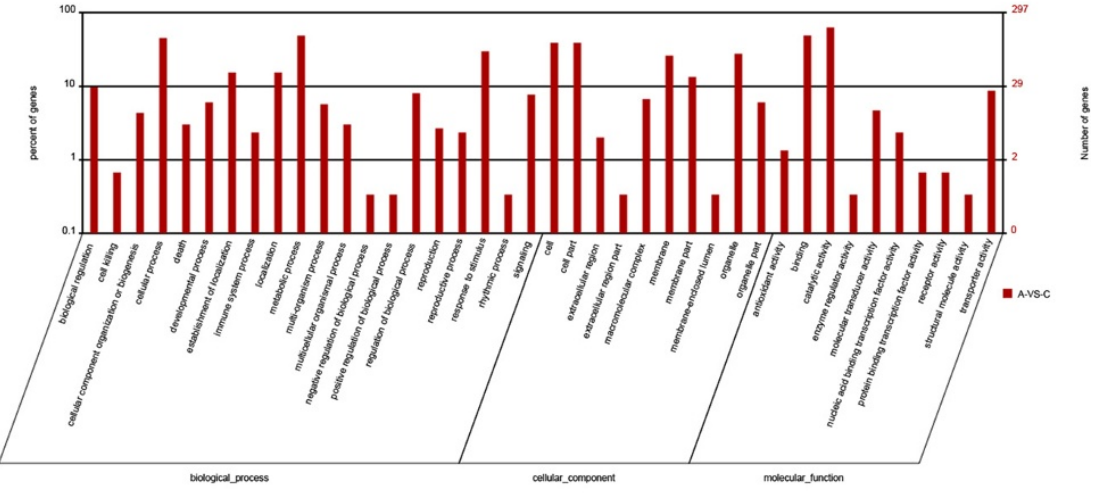

C

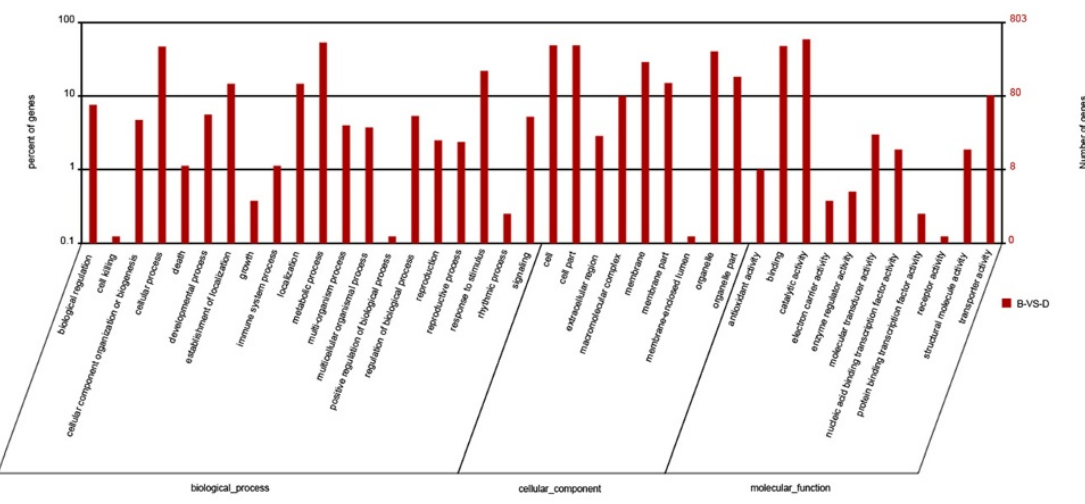

D

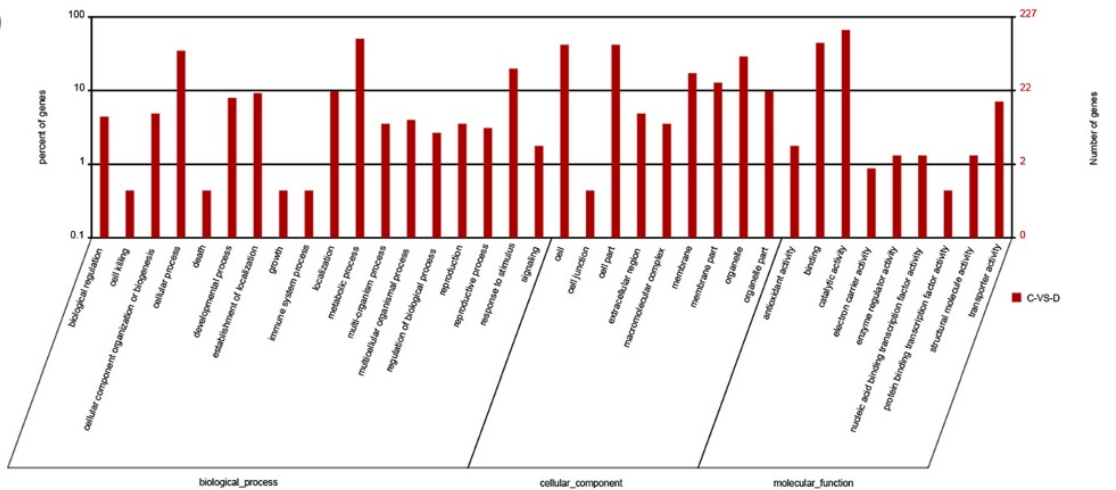

Figure $\mathbf{3}$ (See legend on next page.) 
(See figure on previous page.)

Figure 3 Gene Ontology (GO) classifications of DT genes. DT genes were annotated in three categories: biological process, cellular component and molecular function. Y-axis (right) represents the number of DT genes in each category; Y-axis (left) represents the percentage of a specific category of DT genes within that main category. Panels $\mathbf{A}, \mathbf{B}, \mathbf{C}$ and $\mathbf{D}$ (left) represents DT genes in the contrast between library A (leaf 1 and 4 of plants mockinoculated on leaf 2 and 3 ) and B (mock-treated leaf 2 and 3) (A-VS-B) (right), library A and C (leaf 1 and 4 of plants inoculated by the pathogen on leaf 2 and 3) (A-VS-C) (right), library B and D (pathogen-infected leaf 2 and 3) (B-VS-D) (right), library C and D (C-VS-D) (right), respectively.

in the defence response, a finding which was replicated in the chrysanthemum/A. tenuissima interaction. The RNA-Seq data further show that a large number of genes are involved in the host response between six and $72 \mathrm{~h}$ post inoculation, including several genes involved in the JA and SA pathways. Some of these are discussed in more detail below.

\section{Pathogen recognition-related genes modulated by A. tenuissima infection}

Plant pattern recognition receptors (PRRs) perceive mi crobe-associated molecular patterns (MAMPs), a set of molecular signatures encompassing whole classes of microbes. This recognition initiates a basal level of immunity (termed MAMP-triggered immunity) [23]. Receptor-like kinases (RLKs), which form the largest plant receptor family, are PRRs localized at the plasma membrane [24]. The involvement of RLKs in certain host-pathogen interactions has been well documented experimentally [18]. The RNASeq-based transcriptomic analysis of the lettuce/B. cinerea interaction has revealed that several types of RLK are differentially transcribed [18], and the same phenomenon was recorded in the chrysanthemum/A. tenuissima interaction. The damage caused by microbes can induce the host to synthesize MAMP-like products, termed damageassociated molecular patterns (DAMPs) [23]. Oligogalacturonides (OGs) released from the plant cell wall activate the DAMP-associated response. The induction of an OG receptor wall-associated kinase (WAK) has been suggested as being necessary for the survival $A$. thaliana challenged by pathogen infection [25]. Five WAK-like kinases (encoded by Unigene52017_All, Unigene36001_All, Unigene55763_All, Unigene49198_All and Unigene12436_All) were among the DT genes detected in the $\mathrm{B} v s \mathrm{D}$ contrast (Additional file 11: Table S10), and a sixth (Unigene49 198_All) was identified in the A vs C contrast (Additional file 12: Table S11). Another study showed that WAKs were involved in the immune responses against $B$. cinerea. Furthermore, transgenic plants overexpressing WAK1 conferred resistance to B. cinerea in A. thaliana [26].

Genes encoding a second class of PRR, the leucine-rich repeat RLKs ( $L R R-R L K \mathrm{~s})$, are known to be involved in both basal and cultivar-specific host immunity [27]. In A. thaliana, BRI1 encodes an LRR-RLK which forms a heterodimeric complex with a second LRR-RLK called BAK1 acting as a negative regulator of microbial infection-induced cell death [27]. Bak1 mutants develop spreading necrosis after the triggering of apoptosis by infection with $B$. cinerea [27]. The transcription of two LRR-RLK (Unigene20925_All and Unigene27322_All), four BRI-like (Unigene55939_All, Unigene15368_All, Unigene29292_All, Unigene18133_All), six BAK1 genes (Unigene37501_All, Unigene36228_All, Unigene16709_All, Unigene16958_All, Unigene14705_All, and Unigene27008_All), and two somatic embryogenesis
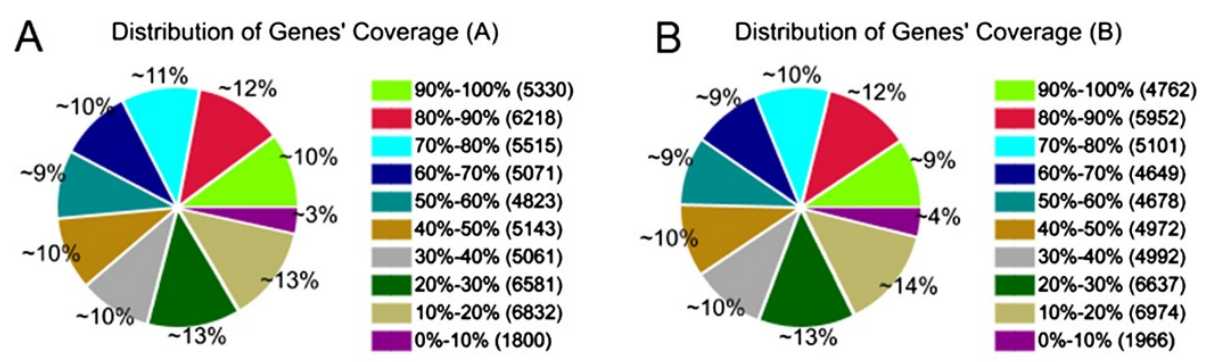

C Distribution of Genes' Coverage (C)
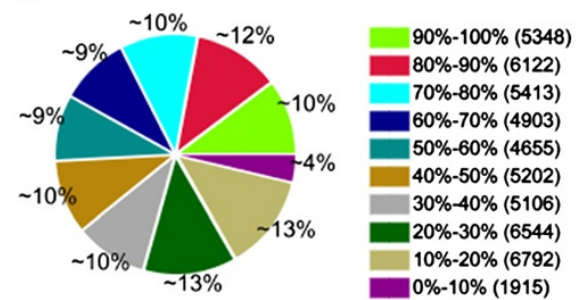

D Distribution of Genes' Coverage (D)
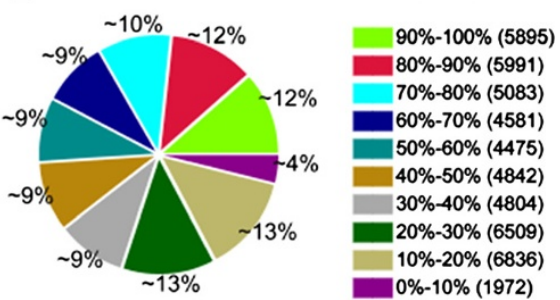

Figure 4 Distribution of gene coverage analysis of each library. Distribution of gene coverage in libraries A, B, C and D. 


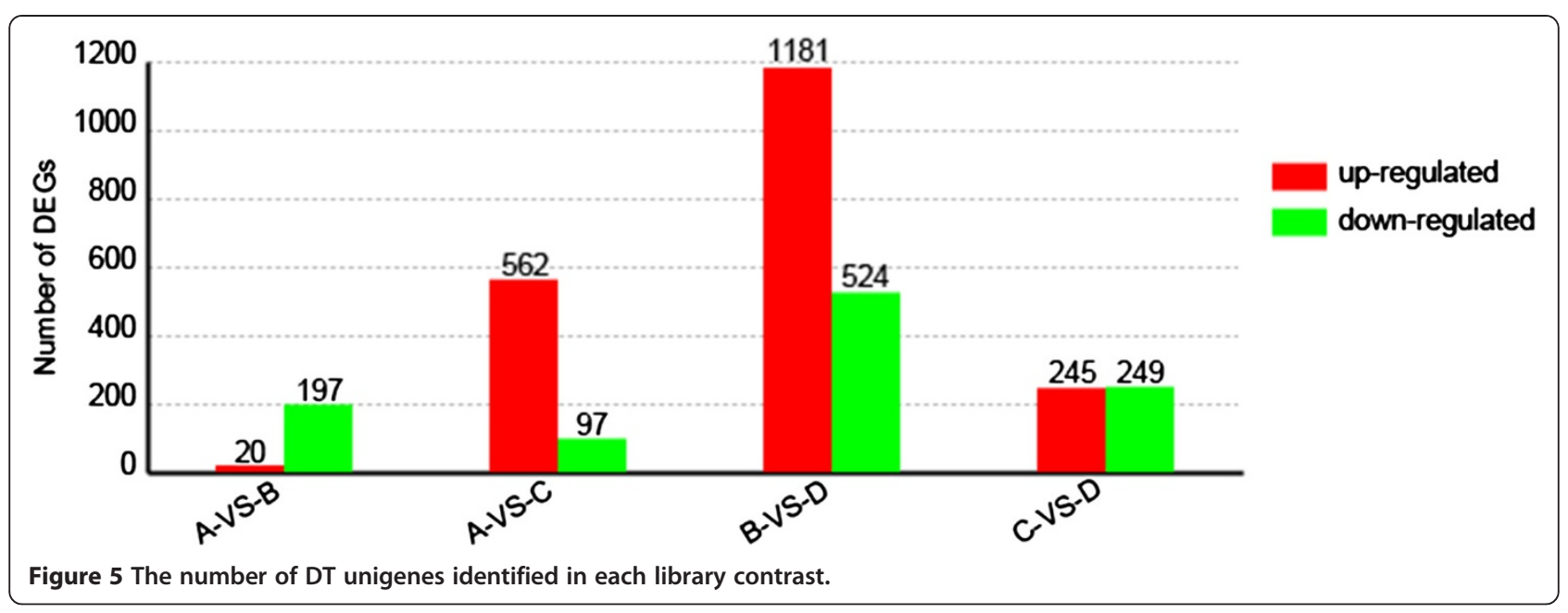

receptor kinase (SERK) genes (Unigene22508_All, Unigene14416_All) was modulated by $A$. tenuissima infection in the B vs D contrast (Additional file 13: Table S12), as were an additional two BRI-like (Unigene15368_All and Unigene4877_All), a somatic embryogenesis receptor kinase (SERK) genes (Unigene22508_All), and four BAK1 genes (Unigene36228_All, Unigene4877_All, Unigene14705_All and Unigene27008_All) in the A vs C contrast (Additional file 12: Table S11). All the above genes were up-regulated except for Unigene18133_All. In the lettuce/B. cinerea interaction, one BRI-like (Lsa034184.1) gene was up-regulated, but no $B A K 1$ genes [18].

The products of genes encoding cysteine-rich receptorlike kinases (CRKS) are RLKs which contain an extracellular cysteine-rich repeat domain. These genes are reportedly activated by oxidative stress, pathogen attack and exposure to SA [18,28-30]. Although less widely researched, they have been characterized to be involved in the pathogen defense and programmed cell death in A. thaliana $[28,30]$. Here, three CRKS were identified as DT genes (Unigene 55939_All, Unigene15489_All and Unigene14705_All) in the B vs D comparison (Additional file 14: Table S13) and a further three (Unigene4299_All, Unigene14705_All and Unigene15489_All) in the A vs C comparison (Additional file 15: Table S14). Thus, PRR-RLKS are clearly involved in the chrysanthemum host response to A. tenuissima infection. The early activation of these genes may reflect their transcription as an attempt by the host to recognize MAMPs/DAMPs.

\section{ROS (reactive oxygen species) detoxification genes modulated by $A$. tenuissima infection}

MAMPs are known to trigger the production of ROS in response to pathogen infection, largely derived from NADPH oxidase activity (commonly referred to as "respiratory burst oxidase homologues" (rboh)) [17,31]. Two chrysanthemum rboh homologues were recognized: Unigene
300_All (homologue of rbohD) and Unigene45792_All $(r b o h F)$; both were differentially transcribed in the B $v s$ D (Additional file 16: Table S15) and A vs C contrasts (Additional file 17: Table S16). The lettuce rbohD homologue (Lsa002796.1) was induced $48 \mathrm{~h}$ after infection with B. cinerea, but its rbohF homologue (Lsa018309.1) was not up-regulated [18]. In A. thaliana, both rbohD and rbohF are required for ROS detoxification [32]. Two further pathogen-inducible $\alpha$-dioxygenases (Unigene32071_All and Unigene12359_All) (Additional file 16: Table S15) were differentially transcribed in the B vs D contrast, and one (Unigene32071_All) in A vs C (Additional file 17: Table S16); this class of gene was also up-regulated in the lettuce/B. cinerea system; its product is involved in protecting the cell against oxidative stress [18].

\section{Genes associated with photosynthesis were mostly down-regulated by $A$. tenuissima infection}

DT genes involved in photosynthesis were uniformly down-regulated in the $\mathrm{B} v s \mathrm{D}$ contrast, with the sole exception of Unigene2020_All (Additional file 18: Table S17). In the contrast $\mathrm{C} v s \mathrm{D}$, four photosynthesis-related DT genes were detected, and all were down-regulated (Additional file 19: Table S18). The response mirrors the outcomes in the lettuce/B. cinerea and lettuce/Verticillium dahliae systems [18,33], as well as in other documented plant-pathogen interactions [34-39]. Unigene6198_All, predicted to be involved in the determination of the plant's circadian clock, was down-regulated in both the B vs D (Additional file 18: Table S17) and C vs D contrasts (Additional file 19: Table S18). Similar examples of the suppression of such genes by pathogen infection have been described in both lettuce [18] and A. thaliana [40]. In the case of $A$. thaliana, $B$. cinerea infection appears to dampen the oscillating transcription of certain core clock components, leading to the suggestion that the pathogen attempts to dampen the host's defence response, 
Table 2 Genes differentially transcribed in 'Zaoyihong' leaves in response to mock-inoculation (B) and A. tenuissima inoculation (D)

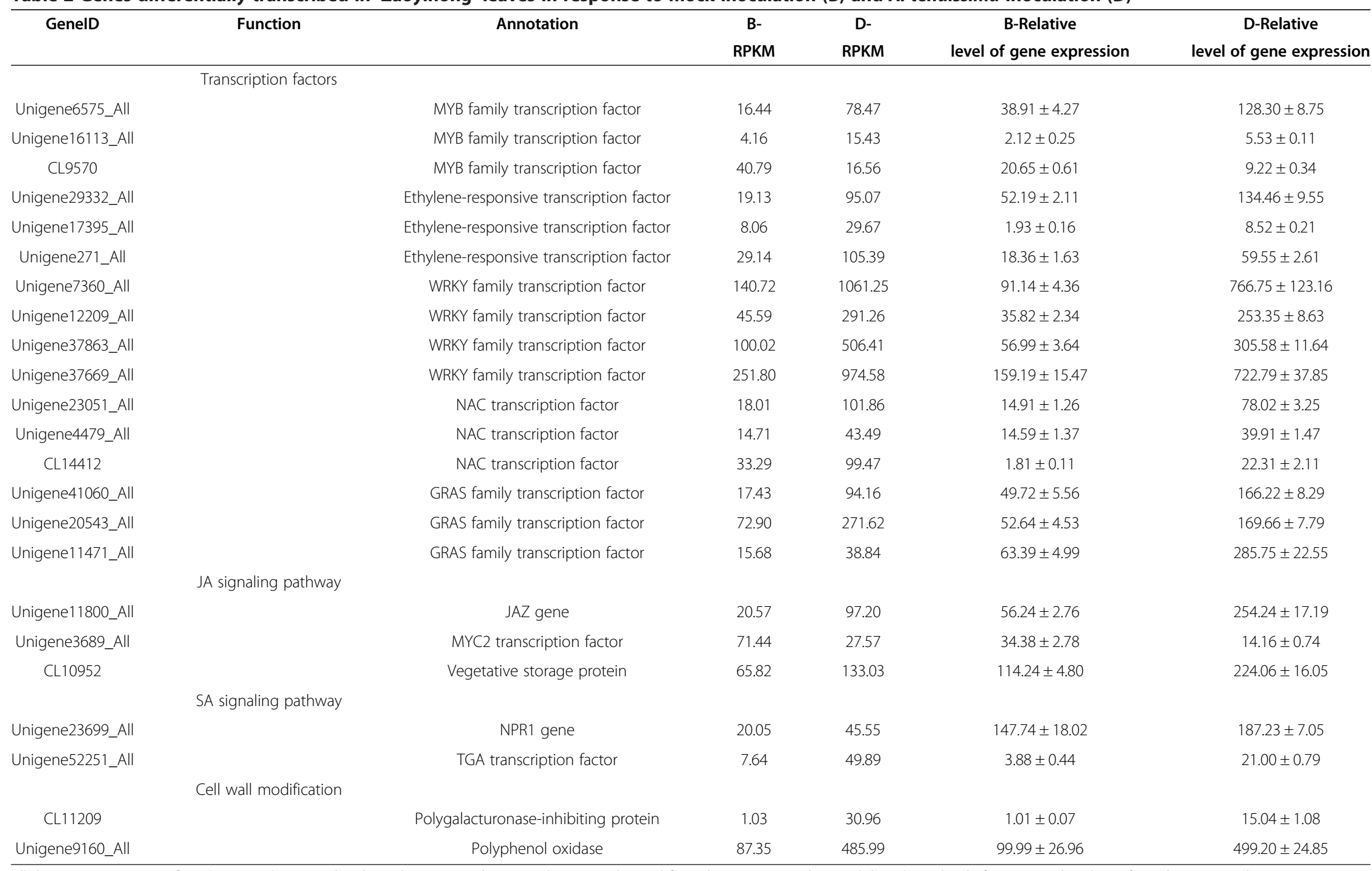

All these genes were significantly up- or down-regulated $(P$ value $<0.05)$. The RPKM data were obtained from the RNA-Seq analysis and the relative level of transcript abundance from the $\mathrm{qPCR}$ analysis. 
because a set of genes associated with plant immune responses was revealed to be regulated by the plant's circadian clock [41].

\section{Genes associated with cell wall protection affected by A. tenuissima infection}

Both PGIP and PPO were up-regulated in response to $A$. tenuissima infection (Table 2). PGIP and PPO are known to respond to various cues [42-48], including the presence of A. solani [42], A. triticina [49], A. macrospora [50], Sclerospora graminicola [51] and Colletotrichum lindemuthianum [52]. PGIP transcript abundance increased over the period 6-24 h after inoculation with $A$. tenuissima (Table 2). Many fungi secrete endo-polygalacturonase, an enzyme which degrades the polysaccharides present in the plant cell wall. Host genes involved in the early defence response include those which help to reinforce the cell wall, and thereby inhibit pathogen entry. PGIP's role in mediating resistance to $A$. alternata infection has been shown in both rough lemon and Japanese pear $[9,53]$, while the growth of $B$. cinerea is restricted in transgenic tomato heterologously expressing pear PGIP [54]. PPO transcription in chrysanthemum was enhanced after inoculation (Table 2), similar to what has been observed in the leaf of Japanese pear inoculated with $A$. alternata [9]. In tomato, the constitutive expression of PPO increases host resistance to Pseudomonas syringae, while its down-regulation enhances susceptibility $[55,56]$.

\section{JA and SA signalling pathway-related genes involved in the response to $A$. tenuissima infection} CmJAZ (Unigene11800_All), CmMYC2 (Unigene3689_All), CmVSP (CL10952), CmNPR1 (Unigene23699_All) and Cm TGA (Unigene52251_All) were all induced by $A$. tenuissima infection (Table 2). NPR1 is a major component of SA signalling, functioning as a co-activator of the TGA transcription factors known to regulate the transcription of various SA-responsive genes [57]. JAZ (jasmonate ZIM domain) proteins repress JA signalling by binding to transcriptional regulators such as MYC2. The degradation of JAZ proteins relieves the JAZ-mediated repression of the JA signalling pathway and thereby activates a large number of JA responsive genes $[57,58]$. JA and SA both play an important part in host defence against herbivorous insects and microbial pathogens. In A. thaliana, VSP2 and PR-1 are, respectively, JA- and SA-responsive proteins [58]. Overall, a number of genes within the JA and SA signalling pathways are involved in the defence response of chrysanthemum against $A$. tenuissima infection.

\section{Transcription factors responding to $A$. tenuissima infection} Transcription factors are central to the control of the timing and placement of defence response gene expression [59]. Their mode of action is to first recognize and then bind to regulatory elements located in the promoter region of their target genes, thereby activating or de-activating their transcription. Here, five classes of transcription factor (MYB, AP2/ERF, WRKY, NAC and GRAS) were identified among the DT genes responding to A. tenuissima infection. In A. thaliana, AtMYB30, AtM $Y B 44$ and $A t M Y B 96$ are all involved in the triggering of apoptosis and therefore resistance against biotrophic bacterial pathogens such as Pseudomonas syringae [60-64]. AtMYB108 is required for resistance against $B$. cinerea and A. brassicicola [65]. The transcription of AtMYB58 has been associated with secondary cell wall formation [66]. Here, one CmMYB copy (Unigene6575_All and a homologue of $A t M Y B 58$ ), was prominently transcribed from $48 \mathrm{~h}$ after inoculation with $A$. tenuissima (Table 2). Therefore, it was speculated that CmMYB (Unigene65 75_All) may be involved in defence response to the necrotrophic fungus $A$. tenuissima through the regulation of secondary cell wall biosynthesis. Modifications to the plant cell wall were already recognized as the potential mechanism of resistance, which was previously provided by the reports on the response of plants to fungal challenges [67]. A second CmMYB (Unigene16113_All, homologous to $A t M Y B 74)$ was also up-regulated by $A$. tenuissima infection (Table 2). In A. thaliana, AtMYB74 reportedly responds to salinity stress and the exogenous supply of abscisic acid, ETH and JA [68], but not as yet to pathogen infection. Therefore, it was speculated that this gene may be involved in defense response to the necrotrophic fungus A. tenuissima and may be also associated with ABA and JA signaling in Chrysanthemum. Other transcription factors in the AP2/ERF, WRKY, NAC and GRAS families were abundantly transcribed in the leaf following $A$. tenuissima inoculation. Many reports have also indicated that four families of transcription factors: MYB proteins, ethylene-responsive-element-binding factors (ERF), WRKY proteins and NAC proteins link to plant stress responses, such as pathogens $[59,60,69-72]$. Little evidence has been provided to date regarding the participation of GRAS transcription factors in the defence response.

In conclusion, it was clear that infection with $A$. tenuissima induced a wide range of genes in the chrysanthemum leaf. The response involved a complex set of interactions between pathogenesis-related genes, genes in the JA and SA signalling pathway and transcription factors. A more detailed understanding of the identity of these genes will help to unravel the molecular basis of the defence response of chrysanthemum to $A$. tenuissima infection, and eventually lead to the recognition of candidates for the targeted genetic improvement of chrysanthemum.

\section{Conclusions}

In this study, we characterized the leaf transcriptome of chrysanthemum and provided the comparative DT genes 
involeved in the interaction between chrysanthemum and $A$. tenuissima. These findings provide a substantial contribution to existing sequence resources of chrysanthemum, and a strong basis for further characterization of gene expression profiles in the interaction of chrysanthemum and A. tenuissima. The majority of the DT genes were those involved in pathogen recognition, reactive oxygen species detoxification, cell wall modification, phytohormone signalling, and transcription factors belonging to various families were also identified, which will improve our understanding of the molecular mechanisms underlining direct response and induced systemic resistance of chrysanthemum to A. tenuissim.

\section{Methods}

Plant materials, A. tenuissima inoculum preparation and inoculation

The chrysanthemum variety 'Zaoyihong' was obtained from the Chrysanthemum Germplasm Resource Preserving Centre, Nanjing Agricultural University, China. Uniform cuttings were propagated in sand, and rooted seedlings transplanted into a 2:1 mixture of garden soil and vermiculite without fertilizer supplementation. The plants were grown under a $16 \mathrm{~h}$ photoperiod with a day/night temperature of, respectively, $25^{\circ} \mathrm{C}$ and $18^{\circ} \mathrm{C}$. The relative humidity was maintained at $68-75 \%$ [3]. A. tenuissima conidia were isolated from diseased chrysanthemum plants, and cultured on potato dextrose agar at $25^{\circ} \mathrm{C}$. An aqueous suspension of $10^{6}$ spores per $\mathrm{ml}$ was prepared with a few drops of Triton X-100 added as a wetting agent [3]. The surface of the second and third true leaves of 20 day old root cuttings was punctured with a needle (approximately $0.30 \mathrm{~mm}$ diameter), and a $10 \mu \mathrm{l}$ droplet of spore suspension was placed on the puncture site. Mock treatments comprised $10 \mu \mathrm{l}$ droplets of sterile distilled water. After inoculation, the plants were held at $100 \%$ relative humidity and $25^{\circ} \mathrm{C}$ in the dark for $24 \mathrm{~h}$, and then illuminated with $120 \mu \mathrm{mol} \mathrm{m}{ }^{-2} \mathrm{~s}^{-1}$ cool white fluorescent light with a $12 \mathrm{~h}$ photoperiod. The leaves of three seedlings were sampled for each treatment at $0 \mathrm{~h}, 6 \mathrm{~h}, 24 \mathrm{~h}, 48 \mathrm{~h}$ and $72 \mathrm{~h}$ after inoculation. The samples collected at defined time points of each treatment were pooled for RNA-seq.

\section{RNA extraction}

Four separate libraries (A-D, see Figure 1) were prepared. Extracts of the second and the third true leaves of

Table 3 Primers of quantitative reverse transcription-polymerase chain reaction for validation of the digital gene expression data

\begin{tabular}{|c|c|c|c|}
\hline Gene ID & Primer $F\left(5^{\prime}-3^{\prime}\right)$ & Primer R (5'-3') & Basic annotation \\
\hline Unigene6575_All & CGGAATCAAGAAAGGTGCAT & ATTCATCCATCGTAGCCTGC & MYB family transcription factor \\
\hline Unigene16113_All & CGTTGTGACGAGAGGAGTGA & CTTCTTCGGATGGGAATTGA & MYB family transcription factor \\
\hline CL9570 & AAAATGCTGGATTGCTGAGG & AAGACCATTTGTTGCCAAGG & MYB family transcription factor \\
\hline Unigene29332_All & CAATTTCATTACCGAGGCGT & TGCCTAGCCATCTTCGAGTT & Ethylene-responsive transcription factor \\
\hline Unigene17395_All & ACGAGATCCCAACAAAGGTG & TTGGACCCTITGAAACGAAG & Ethylene-responsive transcription factor \\
\hline Unigene271_All & CTCTAACTCCGTGCCTCGTC & TTAGAGGGGTTAGGAGGCGT & Ethylene-responsive transcription factor \\
\hline Unigene7360_All & CACCTCGTGGTAGTGGGAGT & TGACTGCCATTATCGGTCAA & WRKY family transcription factor \\
\hline Unigene12209_All & GTGGCTGAGATTGGTGGTT & GCCTTTACAAGCGTTCAGC & WRKY family transcription factor \\
\hline Unigene37863_All & GGATCATCTCAGGGGGATTT & GACAACAGCATCACCACCAC & WRKY family transcription factor \\
\hline Unigene37669_All & TAGATGCACATACCGCAAGG & TTTTCAGGCAAAGGTGGTTC & WRKY family transcription factor \\
\hline Unigene23051_All & ACCTACAAACATCGGCTTCG & CTTCGAAAATGGTGCCCTAA & NAC transcription factor \\
\hline Unigene4479_All & CAGCCAAAAATACCCTGCAT & ACGGACGAAAAACTGATTGG & NAC transcription factor \\
\hline CL14412 & AGTGTCCCTTCACCACCTTCG & CCGTTTCTCGTGACCCTGTT & NAC transcription factor \\
\hline Unigene41060_All & GTAATCTGGAGCATGGGTGG & CTTAATGGTGTGCCCGTTTC & GRAS family transcription factor \\
\hline Unigene20543_All & CTTGTTGCGAAACTGAGCTG & GACCCCTGCTGAAAAGATGA & GRAS family transcription factor \\
\hline Unigene11471_All & TCGAGGGGAAGGAAACACTA & GGTTCTTCACAAGCCGACAT & GRAS family transcription factor \\
\hline Unigene11800_All & AAATGTTCGGTTITCGACG & GATCTTTGTTAGGTGCCGGA & JAZ gene \\
\hline Unigene3689_All & CATTGATGTAACAAACGGCG & AACCAACGCTTCTACACGCT & MYC2 transcription factor \\
\hline CL10952 & CCATTGACCCAAGCAACTTT & TTGAATACGGCTCCTCCATC & Vegetative storage protein \\
\hline Unigene23699_All & CAAAGCATTGGATTGTGACG & TCTAAGATTGACATCCGCCC & NPR1 gene \\
\hline Unigene52251_All & CCGGCTTTGATTGAACTGAT & CGTGGTTCGTGGGTAGAGT & TGA transcription factor \\
\hline CL11209 & GCCGTATAATCGCTCTCACC & CCGGTGAGGTTTGTCAGTIT & Polygalacturonase-inhibiting protein \\
\hline Unigene9160_All & TGAACACAACCAAGATGGGA & CCTCCACCTTGTCCACTGTT & Polyphenol oxidase \\
\hline
\end{tabular}


mock-treated and pathogen-infected plants gave rise to, respectively, libraries $B$ and $D$, while extracts of the first and the fourth noninfected (systemic) true leaves of plants gave rise to libraries $\mathrm{A}$ and $\mathrm{C}$. Total RNA was isolated using a Total RNA Isolation System (Takara, Japan), following the manufacturer's recommendations. The quality of the total RNA (RNA Integrity Number > 6.5 and 28S: $18 \mathrm{~S}>1.0$ ) was verified using a 2100 Bioanalyzer RNA Nano chip device (Agilent, Santa Clara, CA, USA) and its concentration ascertained using an ND-1000 spectrophotometer (NanoDrop, Wilmington, DE). The standards applied were $1.8 \leq \mathrm{OD}_{260 / 280} \leq 2.2$ and $\mathrm{OD}_{260 / 230} \geq 1.8$. At least $10 \mu \mathrm{g}$ RNA was pooled in an equimolar fashion from each of the three sampled plants [73].

\section{cDNA library construction and Illumina sequencing}

Each total RNA extract was first treated with RNase-free DNase I (TaKaRa, Dalian, China) to remove contaminating DNA, and the mRNA content was concentrated by capturing on magnetic oligo (dT) beads. The mRNA was fragmented to a size of $\sim 200 \mathrm{bp}$ using a fragmentation buffer, and the resulting fragments used to synthesize the first cDNA strand by priming with random hexamers. The second strand was generated using a SuperScript Double-Stranded cDNA Synthesis kit (Invitrogen, Camarillo, CA), purified via magnetic beads, the ends repaired and a single adenine base added to the 3' ends. Sequencing adaptors were then ligated to the fragments, and agarose gel electrophoresis used to select the range of fragments suitable for PCR amplification. Sequencing using an Illumina HiSeq 2000 platform was performed at the Beijing Genomics Institute (Shenzhen, China; http://www.genomics.cn/index.php), following the manufacturer's protocols.

\section{Treatment of sequence data}

Raw reads were saved as .fastq files, and filtered to remove adaptor sequences, reads in which the proportion of noncalled bases was $>10 \%$ and reads in which low quality $(\leq 5)$ bases represented $>50 \%$ of the read. The remaining reads were mapped onto the set of chrysanthemum unigene sequences using SOAPaligner/SOAP2 [74]. A maximum of two mismatches was permitted for the purpose of alignment. The frequency of occurrence of individual reads was normalized to RPKM (reads per kb per million reads) [19]. Differential transcription between pathogen-inoculated and mock samples was based on the $\log _{2}$ ratio of the two RPKM values. All raw RNA-Seq data have been deposited at the sequence read archive (SRA) of NCBI (Additional file 20: Table S19).

\section{Identification of DT genes}

Following Audic and Claverie (1997) [20], a stringent algorithm was developed to identify DT genes. The FDR (false discovery rate) provides a criterion to determine the $P$-value threshold in multiple tests and analyses by manipulating the FDR value. Here, differential transcription was declared provided that the $P$-value was $<0.05$, the FDR $\leq 0.001$ and the absolute value of $\log _{2}$ induction ratios of treated samples compared with mock-treatment or control (CK) was $\geq$ 1.0. Standard gene ontology (GO) was used to describe DT gene functionality, and a hypergeometric test was used to map the DT genes to GO terms based on the BGI WEGO (Web Gene Ontology Annotation Plot, http:// wego.genomics.org.cn/cgi-bin/wego/index.pl).

\section{Quantitative real-time PCR (qPCR) validation}

The transcription of 23 selected candidate genes was determined using quantitative real time PCR (qPCR). The samples collected at different time points were pooled, which were used for qPCR analysis, contaminating DNA removed by RNase-free DNase I treatment and the first cDNA strand synthesized using a Super RT kit (BioTeke, Beijing, China). A set of gene-specific primer pairs (sequences given in Table 3) was designed using Primer3 software [18,75]. qPCRs were based on SYBR_Green I (TOYOBO', Japan) implemented in a Rotor-Gene 3000 device (Corbett, Australia). The chrysanthemum EF1 $\alpha$ gene was used as a reference. Each $25 \mu \mathrm{l}$ qPCR reaction contained $10 \mu \mathrm{l}$ SYBR Green PCR master mix, $0.2 \mu \mathrm{M}$ of each primer and $10 \mathrm{ng}$ cDNA, and the amplification regime consisted of an initial denaturation of $95^{\circ} \mathrm{C} / 60 \mathrm{~s}$, followed by 40 cycles of $95^{\circ} \mathrm{C} /$ $15 \mathrm{~s}, 55^{\circ} \mathrm{C} / 15 \mathrm{~s}, 72^{\circ} \mathrm{C} / 20 \mathrm{~s}$. Transcript abundances are given as the mean $\pm \mathrm{SE}$ of three replicates. Relative transcription levels were calculated using the $2^{-\triangle \Delta C T}$ method [76].

\section{Additional files}

Additional file 1: Figure S1. Composition of the raw reads in the fou RNA libraries. "Clean" reads are those remaining after removal of adaptor sequences, reads in which the proportion of non-called bases was $>10 \%$ and reads in which low quality $(\leq 5)$ bases represented $>50 \%$ of the reads. The numbers in parentheses indicate the percentage of each type of read present.

Additional file 2: Table S1. GO classification of the genes differentially transcribed in the contrast between libraries $\mathrm{A}$ and $\mathrm{B}$.

Additional file 3: Table S2. GO classification of the genes differentially transcribed in the contrast between libraries $A$ and $C$.

Additional file 4: Table S3. GO classification of the genes differentially transcribed in the contrast between libraries B and D.

Additional file 5: Table S4. GO classification of the genes differentially transcribed in the contrast between libraries $C$ and D.

Additional file 6: Table S5. Genes differentially transcribed in the contrast between libraries $A$ and $B$. The criteria applied for assigning significance were: $P$-value $<0.05$, FDR $\leq 0.001$, and estimated absolute $\mid \log _{2}$ Ratio(B/A) $\mid \geq 1$. Genes listed in descending order of absolute $\left|\log _{2} \operatorname{Ratio}(B / A)\right|$. GenelDs retrieved from the Chrysanthemum Reference Sequence Database. Annotation of unigene sequences performed using BlastX ( $E<10)$. The "GeneLength" column gives the length of exon sequence. $A$ - and $B$ expression: frequency of unigene transcripts in libraries $A$ and $B$, respectively. A- and B-RPKM: reads per kb per million reads for each unigene in libraries $A$ and $B$, respectively. $\log _{2}$ Ratio (B/A): the ratio between the RPKM in B and the RPKM in A. Up-DownRegulation(B/A), P-value and FDR of each gene are also shown. KEGG: 
annotation according to the KEGG database by BLAST. Blast nr: identification of homologues in GenBank. GO Component, GO Function and Go Process: ontology information of Cellular Components, Molecular Function and Biological Processes of Gene-corresponding GO terms. "-": no hit.

Additional file 7: Table S6. Genes differentially transcribed in the contrast between libraries $\mathrm{A}$ and $\mathrm{C}$. The criteria applied for assigning significance were: $P$-value $<0.05, \mathrm{FDR} \leq 0.001$, and estimated absolute | $\log _{2} \operatorname{Ratio}(C / A) \mid \geq 1$. Genes listed in descending order of absolute | $\log _{2}$ Ratio(C/A)|. GenelDs retrieved from the Chrysanthemum Reference Sequence Database. Annotation of unigene sequences performed using BlastX ( $E<10)$. The "GeneLength" column gives the length of exon sequence. $\mathrm{A}$ - and $\mathrm{C}$ expression: frequency of unigene transcripts in libraries A and C, respectively. A- and C-RPKM: reads per kb per million reads for each unigene in libraries $A$ and $C$, respectively. $\log _{2}$ Ratio(C/A): the ratio between the RPKM in C and the RPKM in A. Up-DownRegulation(C/A), $P$-value and FDR of each gene are also shown. KEGG: annotation according to the KEGG database by BLAST. Blast nr: identification of homologues in GenBank. GO Component, GO Function and Go Process: ontology information of Cellular Components, Molecular Function and Biological Processes of Gene-corresponding GO terms. "-": no hit.

Additional file 8: Table S7. Genes differentially transcribed in the contrast between libraries $\mathrm{B}$ and $\mathrm{D}$. The criteria applied for assigning significance were: $P$-value $<0.05, \mathrm{FDR} \leq 0.001$, and estimated absolute | $\log _{2} \operatorname{Ratio}(D / B) \mid \geq 1$. Genes listed in descending order of absolute | $\log _{2}$ Ratio(D/B)|. GenelDs retrieved from the Chrysanthemum Reference Sequence Database. Annotation of unigene sequences performed using BlastX $(E<10)$. The "GeneLength" column gives the length of exon sequence. $B$ - and $D$ expression: frequency of unigene transcripts in libraries $B$ and $D$, respectively. B- and D-RPKM: reads per $k b$ per million reads for each unigene in libraries $B$ and $D$, respectively. $\log _{2} \operatorname{Ratio}(D / B)$ : the ratio between the RPKM in D and the RPKM in B. Up-Down-Regulation(D/B), $P$-value and FDR of each gene are also shown. KEGG: annotation according to the KEGG database by BLAST. Blast nr: identification of homologues in GenBank. GO Component, GO Function and Go Process: ontology information of Cellular Components, Molecular Function and Biological Processes of Gene-corresponding GO terms. "-": no hit.

Additional file 9: Table S8. Genes differentially transcribed in the contrast between libraries $C$ and D. The criteria applied for assigning significance were: $P$-value $<0.05, \mathrm{FDR} \leq 0.001$, and estimated absolute | $\log _{2}$ Ratio(D/C) $\mid \geq 1$. Genes listed in descending order of absolute | $\log _{2}$ Ratio(D/C)|. GenelDs retrieved from the Chrysanthemum Reference Sequence Database. Annotation of unigene sequences performed using BlastX $(E<10)$. The "GeneLength" column gives the length of exon sequence. $C$ - and D expression: frequency of unigene transcripts in libraries $C$ and D, respectively. C- and D-RPKM: reads per kb per million reads for each unigene in libraries $C$ and $D$, respectively. $\log _{2}$ Ratio(D/C): the ratio between the RPKM in D and the RPKM in C. Up-DownRegulation(D/C), P-value and FDR of each gene are also shown. KEGG: annotation according to the KEGG database by BLAST. Blast nr: identification of homologues in GenBank. GO Component, GO Function and Go Process: ontology information of Cellular Components, Molecular Function and Biological Processes of Gene-corresponding GO terms. "-": no hit.

Additional file 10: Table S9. The transcription level of each unigene derived from the number of relevant reads recovered in the four libraries. The "GeneLength" column gives the length of exon sequence.

Additional file 11: Table S10. The differential transcription of Wallassociated receptor kinase-like (WAK-like) genes in the contrast B vs D. The criteria applied for assigning significance were: $P$-value $<0.05$, FDR $\leq$ 0.001 , and estimated absolute $\left|\log _{2}^{\text {Ratio(D/B) }}\right| \geq 1$. RPKM: reads per $\mathrm{kb}$ per million reads.

Additional file 12: Table S11. The differential transcription of Wallassociated receptor kinase-like (WAK-like), brassinosteroid insensitive 1 (BR-like), somatic embryogenesis receptor kinase (SERK), and BRI1-associated receptor kinase 1 (BAK1) genes in the contrast A vS $C$. The criteria applied for assigning significance were: $P$-value $<0.05, F D R \leq 0.001$, and estimated absolute $\| \log _{2}^{\text {Ratio( }(C A)} \mid \geq 1$. RPKM: reads per kb per million reads.

Additional file 13: Table S12. The differential transcription of leucinerich repeat receptor-like kinase ( $L R R-R L K)$, brassinosteroid insensitive 1
(BRI-like), BRI1-associated receptor kinase 1 (BAK1), and somatic embryogenesis receptor kinase (SERK) genes in the contrast $B$ vs $D$. The criteria applied for assigning significance were: $P$-value $<0.05, \mathrm{FDR} \leq 0.001$, and estimated absolute $\left|\log _{2}^{\text {Ratio(D/B })}\right| \geq 1$. RPKM: reads per kb per million reads.

Additional file 14: Table S13. The differential transcription of cysteinerich receptor-like protein kinase (CRKS) genes in the contrast B vs D. The criteria applied for assigning significance were: $P$-value $<0.05, F D R \leq 0.001$, and estimated absolute $\left|\log _{2}^{\text {Ratio(D/B) }}\right| \geq 1$. RPKM: reads per $k b$ per million reads.

Additional file 15: Table S14. The differential transcription of cysteinerich receptor-like protein kinase (CRKS) genes in the contrast A vs $C$. The criteria applied for assigning significance were: $P$-value $<0.05, F D R \leq 0.001$, and estimated absolute $\left|\log _{2}^{\text {Ratio( }(C / A)}\right| \geq 1$. RPKM: reads per $k b$ per million reads.

Additional file 16: Table S15. The differential transcription of respiratory burst oxidase, and alpha-dioxygenase genes in the contrast B vs D. The criteria applied for assigning significance were: $P$-value $<0.05, F D R \leq 0.001$, and estimated absolute $\left|\log _{2}^{\text {Ratio(D/B })}\right| \geq 1$. RPKM: reads per kb per million reads.

Additional file 17: Table S16. The differential transcription of respiratory burst oxidase, and alpha-dioxygenase genes in the contrast A vs $C$. The criteria applied for assigning significance were: $P$-value $<0.05, F D R \leq 0.001$, and estimated absolute $\left|\log _{2}^{\text {Ratio( }(C A)}\right| \geq 1$. RPKM: reads per $\mathrm{kb}$ per million reads.

Additional file 18: Table S17. The differential transcription of photosynthesis and circadian rhythm-related genes in the contrast B vs D. The criteria applied for assigning significance were: $P$-value $<0.05, F D R \leq 0.001$, and estimated absolute $\left|\log _{2}^{\text {Ratio( }(D / B)}\right| \geq 1$. RPKM: reads per kb per million reads.

Additional file 19: Table S18. The differential transcription of photosynthesis and circadian rhythm-related genes in the contrast C vs D. The criteria applied for assigning significance were: $P$-value $<0.05$, FDR $\leq 0.001$, and estimated absolute $\left|\log _{2}^{\text {Ratio(D/C) }}\right| \geq 1$. RPKM: reads per kb per million reads.

Additional file 20: Table S19. High-throughput sequencing metadata.

\section{Competing interests}

The authors declare that they have no competing interests.

\section{Authors' contributions}

$L H Y$ and SAP contributed to RACE PCR, real-time PCR, bioinformatics analysis and writing of the manuscript. CFD, JJF and CSM conceived of the study, and participated in its design and contributed to revisions of the manuscript. FWM and GZY participated in experiment materials preparation. WHB helped with the RNA extraction. All authors read and approved the final manuscript.

\section{Acknowledgment}

This work was supported by funding from the Program for New Century Excellent Talents in University of Chinese Ministry of Education (NCET-10-0492, NCET-12-0890, NCET-11-0669), the National Natural Science Foundation of China (31272196), the Natural Science Fund of Jiangsu Province (BK201164, BK2012773), 948 Project of Ministry of Agriculture (2011-G17, 2013-S13), Fund for Independent Innovation of Agricultural Sciences in Jiangsu Province [CX(12)2020], the Program for Hi-Tech Research, Jiangsu, China, (BE2012350,BE2011325), and the Youth Science and Technology Innovation Fund from Nanjing Agricultural University (KJ2011009).

Received: 21 September 2013 Accepted: 21 December 2013 Published: 4 January 2014

\section{References}

1. Shibata M: Importance of genetic transformation in ornamental plant breeding. Plant Biotechnol 2008, 25(1):3-8.

2. Teixeira da Silva JA, Shinoyama H, Aida R, Matsushita Y, Raj SK, Chen F: Chrysanthemum Biotechnology: Quo vadis? Crit Rev Plant Sci 2013, 32(1):21-52.

3. Xu G, Liu Y, Chen S, Chen F: Potential structural and biochemical mechanisms of compositae wild species resistance to Alternaria tenuissima. Russ J Plant Phys ++2011 , 58(3):491-497.

4. Deng Y, Chen S, Chang Q, Wang H, Chen F: The chrysanthemum $\times$ Artemisia vulgaris intergeneric hybrid has better rooting ability and higher resistance to alternaria leaf spot than its chrysanthemum parent. Sci Hortic-Amsterdam 2012, 134:185-190. 
5. Mirkova $\mathrm{E}$, Konstantinova P: First report of Alternaria leaf spot on gerbera (Gerbera jamesonii H. Bolux ex JD Hook) in Bulgaria. J Phytopathol 2003, 15(6):323-328.

6. Mukherjee AK, Carp MJ, Zuchman R, Ziv T, Horwitz BA, Gepstein S: Proteornics of the response of Arabidopsis thaliana to infection with Alternaria brassicicola. J Proteomics 2010, 73(4):709-720.

7. Jia C, Zhang L, Liu L, Wang J, Li C, Wang Q: Multiple phytohormone signalling pathways modulate susceptibility of tomato plants to Alternaria alternata f. sp. lycopersici. J Exp Bot 2013, 64(2):637-650.

8. Sinha R, Chattopadhyay S: Changes in the leaf Proteome profile of Mentha arvensis in response to Alternaria alternata infection. $J$ Proteomics 2011, 74(3):327-336.

9. Egusa M, Ochi $H$, Tsuge $T$, Otani $H$, Kodama M: Identification of putative defense-related genes in Japanese pear against Alternaria alternata infection using suppression subtractive hybridization and expression analysis. J Gen Plant Pathol 2009, 75(2):119-124.

10. Kulye M, Liu H, Zhang Y, Zeng H, Yang X, Qiu D: Hrip1, a novel protein elicitor from necrotrophic fungus, Alternaria tenuissima, elicits cell death, expression of defence-related genes and systemic acquired resistance in tobacco. Plant Cell Environ 2012, 35(12):2104-2120.

11. Yano A, Suzuki K, Uchimiya H, Shinshi H: Induction of hypersensitive cell death by a fungal protein in cultures of tobacco cells. Mol Plant Microbe In 1998, 11(2):115-123.

12. Garcia-Brugger A, Lamotte $O$, Vandelle E, Bourque $S$, Lecourieux D, Poinssot B, Wendehenne D, Pugin A: Early signaling events induced by elicitors of plant defenses. Mol Plant Microbe In 2006, 19(7):711-724.

13. landolino A, Nobuta K, Goes da Silva F, Cook DR, Meyers BC: Comparative expression profiling in grape (Vitis vinifera) berries derived from frequency analysis of ESTs and MPSS signatures. BMC Plant Biol 2008, 8(1):1-16.

14. Vizoso P, Meisel LA, Tittarelli A, Latorre M, Saba J, Caroca R, Maldonado J, Cambiazo V, Campos-Vargas R, Gonzalez M: Comparative EST transcript profiling of peach fruits under different post-harvest conditions reveals candidate genes associated with peach fruit quality. BMC Genomics 2009, 10:423-440.

15. Wang QQ, Liu F, Chen XS, Ma XJ, Zeng HQ, Yang ZM: Transcriptome profiling of early developing cotton fiber by deep-sequencing reveals significantly differential expression of genes in a fuzzless/lintless mutant. Genomics 2010, 96(6):369-376.

16. $\mathrm{Xu} \mathrm{L,} \mathrm{Zhu} \mathrm{L,} \mathrm{Tu} \mathrm{L,} \mathrm{Liu} \mathrm{L,} \mathrm{Yuan} \mathrm{D,} \mathrm{Jin} \mathrm{L,} \mathrm{Long} \mathrm{L,} \mathrm{Zhang} \mathrm{X:} \mathrm{Lignin} \mathrm{metabolism}$ has a central role in the resistance of cotton to the wilt fungus Verticillium dahliae as revealed by RNA-Seq-dependent transcriptional analysis and histochemistry. J Exp Bot 2011, 62(15):5607-5621.

17. Li CY, Deng GM, Yang J, Viljoen A, Jin Y, Kuang RB, Zuo CW, Lv ZC, Yang QS, Sheng $O$, et al: Transcriptome profiling of resistant and susceptible Cavendish banana roots following inoculation with Fusarium oxysporum f. sp. cubense tropical race 4. BMC Genomics 2012, 13:374-384.

18. de Cremer K, Mathys J, Vos C, Froenicke L, Michelmore RW, Cammue B, de Coninck B: RNAseq-based transcriptome analysis of Lactuca sativa infected by the fungal necrotroph Botrytis cinerea. Plant Cell Environ 2013, 36:1992-2007.

19. Mortazavi A, Williams BA, McCue K, Schaeffer L, Wold B: Mapping and quantifying mammalian transcriptomes by RNA-Seq. Nat Methods 2008, 5(7):621-628.

20. Audic S, Claverie JM: The significance of digital gene expression profiles. Genome Res 1997, 7(10):986-995.

21. Ferrari S, Galletti R, Denoux C, de Lorenzo G, Ausubel FM, Dewdney J: Resistance to Botrytis cinerea induced in Arabidopsis by elicitors is independent of salicylic acid, ethylene, or jasmonate signaling but requires PHYTOALEXIN DEFICIENT3. Plant Physiol 2007, 144(1):367-379.

22. Mulema JM, Denby KJ: Spatial and temporal transcriptomic analysis of the Arabidopsis thaliana-Botrytis cinerea interaction. Mol Biol Rep 2012, 39(4):4039-4049.

23. Boller T, Felix G: A Renaissance of Elicitors: Perception of Microbe-Associated Molecular Patterns and Danger Signals by Pattern-Recognition Receptors. Annu Rev Plant Biol 2009, 60:379-406.

24. Toer M, Lotze MT, Holton N: Receptor-mediated signalling in plants: molecular patterns and programmes. J Exp Bot 2009, 60(13):3645-3654

25. He ZH, He DZ, Kohorn BD: Requirement for the induced expression of a cell wall associated receptor kinase for survival during the pathogen response. Plant J 1998, 14(1):55-63.
26. Brutus A, Sicilia F, Macone A, Cervone F, de Lorenzo G: A domain swap approach reveals a role of the plant wall-associated kinase 1 (WAK1) as a receptor of oligogalacturonides. Proc Natl Acad Sci U S A 2010, 107(20):9452-9457.

27. Kemmerling B, Schwedt A, Rodriguez P, Mazzotta S, Frank M, Qamar SA, Mengiste T, Betsuyaku S, Parker JE, Müssig C: The BRI1-associated kinase 1, BAK1, has a brassinolide-independent role in plant cell-death control. Curr Biol 2007, 17(13):1116-1122.

28. Czernic P, Visser B, Sun WN, Savoure A, Deslandes L, Marco Y, van Montagu M, Verbruggen N: Characterization of an Arabidopsis thaliana receptor-like protein kinase gene activated by oxidative stress and pathogen attack. Plant J 1999, 18(3):321-327.

29. Chen KG, Du LQ, Chen ZX: Sensitization of defense responses and activation of programmed cell death by a pathogen-induced receptorlike protein kinase in Arabidopsis. Plant Mol Biol 2003, 53(1):61-74.

30. Chen KG, Fan BF, Du LQ, Chen ZX: Activation of hypersensitive cell death by pathogen-induced receptor-like protein kinases from Arabidopsis. Plant Mol Biol 2004, 56(2):271-283.

31. Torres MA, Jones JD, Dangl $\mathrm{J}$ : Reactive oxygen species signaling in response to pathogens. Plant Physiol 2006, 141(2):373-378.

32. Torres MA, Dangl JL, Jones JD: Arabidopsis gp91phox homologues AtrbohD and AtrbohF are required for accumulation of reactive oxygen intermediates in the plant defense response. Proc Natl Acad Sci USA 2002, 99(1):517-522.

33. Klosterman SJ, Anchieta A, Garcia-Pedrajas MD, Maruthachalam K, Hayes RJ, Subbarao KV: SSH reveals a linkage between a senescence-associated protease and Verticillium wilt symptom development in lettuce (Lactuca sativa). Physiol Mol Plant P 2011, 76(1):48-58.

34. Milli A, Cecconi D, Bortesi L, Persi A, Rinalducci S, Zamboni A, Zoccatelli G, Lovato A, Zolla L, Polverari A: Proteomic analysis of the compatible interaction between Vitis vinifera and Plasmopara viticola. J Proteomics 2012, 75(4):1284-1302.

35. Gyetvai G, Sonderkaer M, Goebel U, Basekow R, Ballvora A, Imhoff M, Kersten B, Nielsen KL, Gebhardt C: The transcriptome of compatible and incompatible interactions of potato (Solanum tuberosum) with Phytophthora infestans revealed by DeepSAGE analysis. PLoS One 2012, 7(2):e31526.

36. Bonfig KB, Gabler A, Simon UK, Luschin-Ebengreuth N, Hatz M, Berger S, Muhammad N, Zeier J, Sinha AK, Roitsch T: Post-translational derepression of invertase activity in source leaves via down-regulation of invertase inhibitor expression is part of the plant defense response. Mol Plant 2010, 3(6):1037-1048.

37. Swarbrick PJ, Schulze-Lefert P, Scholes JD: Metabolic consequences of susceptibility and resistance (race-specific and broad-spectrum) in barley leaves challenged with powdery mildew. Plant Cell Environ 2006, 29(6):1061-1076.

38. Scharte J, Schon H, Weis E: Photosynthesis and carbohydrate metabolism in tobacco leaves during an incompatible interaction with Phytophthora nicotianae. Plant Cell Environ 2005, 28(11):1421-1435.

39. Chou H-M, Bundock N, Rolfe SA, Scholes JD: Infection of Arabidopsis thaliana leaves with Albugo candida (white blister rust) causes a reprogramming of host metabolism. Mol Plant Pathol 2000, 1(2):99-113.

40. Windram O, Madhou P, McHattie S, Hill C, Hickman R, Cooke E, Jenkins DJ, Penfold CA, Baxter L, Breeze E, et al: Arabidopsis defense against Botrytis cinerea: chronology and regulation deciphered by high-resolution temporal transcriptomic analysis. Plant Cell 2012, 24(9):3530-3557.

41. Wang W, Barnaby JY, Tada Y, Li H, Tör M, Caldelari D, du Lee FXD, Dong X: Timing of plant immune responses by a central circadian regulator. Nature 2011, 470(7332):110-114.

42. Thipyapong P, Steffens JC: Tomato polyphenol oxidase (differential response of the polyphenol oxidase $\mathrm{F}$ promoter to injuries and wound signals). Plant Physiol 1997, 115(2):409-418.

43. Ferrari S, Sella L, Janni M, de Lorenzo G, Favaron F, D'Ovidio R: Transgenic expression of polygalacturonase-inhibiting proteins in Arabidopsis and wheat increases resistance to the flower pathogen Fusarium graminearum. Plant Biol 2012, 14:31-38.

44. Shetty SM, Chandrashekar A, Venkatesh YP: Promoter analyses and transcriptional profiling of eggplant polyphenol oxidase 1 gene (SmePPO1) reveal differential response to exogenous methyl jasmonate and salicylic acid. J Plant Physiol 2012, 169:718-730.

45. Bhonwong A, Stout MJ, Attajarusit J, Tantasawat P: Defensive role of tomato polyphenol oxidases against cotton bollworm (Helicoverpa armigera) and beet armyworm (Spodoptera exigua). J Chem Ecol 2009, 35(1):28-38. 
46. Mahanil S, Attajarusit J, Stout MJ, Thipyapong P: Overexpression of tomato polyphenol oxidase increases resistance to common cutworm. Plant Sci 2008, 174(4):456-466.

47. Wang J, Constabel CP: Polyphenol oxidase overexpression in transgenic Populus enhances resistance to herbivory by forest tent caterpillar (Malacosoma disstria). Planta 2004, 220(1):87-96.

48. Thipyapong P, Hunt MD, Steffens JC: Systemic wound induction of potato (Solanum tuberosum) polyphenol oxidase. Phytochemistry 1995, 40(3):673-676

49. Tyagi M, Kayastha AM, Sinha B: The role of peroxidase and polyphenol oxidase isozymes in wheat resistance to Alternaria triticina. Biol Plantarum 2000, 43(4):559-562.

50. Bashan Y: Phenols in cotton seedlings resistant and susceptible to Alternaria macrospora. J Phytopathol 1986, 116:1-10.

51. Niranjan RAJS, Sarosh B, Shetty H: Induction and accumulation of polyphenol oxidase activities as implicated in development of resistance against pearl millet downy mildew disease. Funct Plant Biol 2006, 33(6):563-571

52. Campos A, Ferreira A, Hampe M, Antunes I, Brancao N, Silveira E, Osorio V, Augustin E: Peroxidases and polyphenol oxidase activity in bean anthracnose resistance. Pesqui Agropecu Bras 2004, 39:637-643.

53. Gotoh Y, Nalumpang S, Isshiki A, Utsumi T, Gomi K, Yamamoto H, Akimitsu K: A cDNA encoding polygalacturonase-inhibiting protein induced in citrus leaves by polygalacturonase of Alternaria citri. J Gen Plant Pathol 2002, 68(1):57-61.

54. Powell AL, van Kan J, ten Have A, Visser J, Greve LC, Bennett AB, Labavitch JM: Transgenic expression of pear PGIP in tomato limits fungal colonization. Mol Plant Microbe In 2000, 13(9):942-950.

55. Li L, Steffens JC: Overexpression of polyphenol oxidase in transgenic tomato plants results in enhanced bacterial disease resistance. Planta 2002, 215(2):239-247.

56. Thipyapong P, Hunt MD, Steffens JC: Antisense downregulation of polyphenol oxidase results in enhanced disease susceptibility. Planta 2004, 220(1):105-117.

57. Ballaré CL: Jasmonate-induced defenses: a tale of intelligence, collaborators and rascals. Trends Plant Sci 2011, 16(5):249-257.

58. Leon-Reyes A, van der Does D, de lange ES, Delker C, Wasternack C, van Wees CSM, Ritsema T, Pieterse CMJ: Salicylate-mediated suppression of jasmonate-responsive gene expression in Arabidopsis is targeted downstream of the jasmonate biosynthesis pathway. Planta 2010, 232(6):1423-1432

59. Singh KB, Foley RC, Oñate-Sánchez L: Transcription factors in plant defense and stress responses. Curr Opin Plant Biol 2002, 5(5):430-436.

60. Dubos C, Stracke R, Grotewold E, Weisshaar B, Martin C, Lepiniec L: MYB transcription factors in Arabidopsis. Trends Plant Sci 2010, 15(10):573-581.

61. Vailleau F, Daniel $X$, Tronchet M, Montillet J-L, Triantaphylidès C, Roby D: A R2R3-MYB gene, AtMYB30, acts as a positive regulator of the hypersensitive cell death program in plants in response to pathogen attack. Proc Natl Acad Sci U S A 2002, 99(15):10179-10184.

62. Shim JS, Jung C, Lee S, Min K, Lee YW, Choi Y, Lee JS, Song JT, Kim JK, Choi YD: AtMYB44 regulates WRKY70 expression and modulates antagonistic interaction between salicylic acid and jasmonic acid signaling. Plant J 2013, 73(3):483-495.

63. Zou B, Jia Z, Tian S, Wang X, Gou Z, Lü B, Dong H: AtMYB44 positively modulates disease resistance to Pseudomonas syringae through the salicylic acid signalling pathway in Arabidopsis. Funct Plant Biol 2012, 40(3):304-313.

64. Seo PJ, Park CM: MYB96-mediated abscisic acid signals induce pathogen resistance response by promoting salicylic acid biosynthesis in Arabidopsis. New Phytol 2010, 186(2):471-483.

65. Mengiste T, Chen X, Salmeron J, Dietrich R: The BOTRYTIS SUSCEPTIBLE1 gene encodes an R2R3MYB transcription factor protein that is required for biotic and abiotic stress responses in Arabidopsis. Plant Cell 2003, 15(11):2551-2565.

66. Zhou J, Lee C, Zhong R, Ye ZH: MYB58 and MYB63 are transcriptional activators of the lignin biosynthetic pathway during secondary cell wall formation in Arabidopsis. Plant Cell 2009, 21(1):248-266.

67. Ramírez V, Agorio A, Coego A, García-Andrade J, Hernández MJ, Balaguer B, Ouwerkerk PB, Zarra I, Vera P: MYB46 modulates disease susceptibility to Botrytis cinerea in Arabidopsis. Plant Physiol 2011, 155(4):1920-1935.
68. Yanhui C, Xiaoyuan Y, Kun H, Meihua L, Jigang L, Zhaofeng G, Zhiqiang L, Yunfei Z, Xiaoxiao W, Xiaoming Q: The MYB transcription factor superfamily of Arabidopsis: expression analysis and phylogenetic comparison with the rice MYB family. Plant Mol Biol 2006, 60(1):107-124.

69. Du H, Yang SS, Feng BR, Tang YX, Huang YB, Liang Z: Genome-wide analysis of the MYB transcription factor superfamily in soybean. BMC Plant Biol 2012, 12(1):106-127.

70. Zheng Z, Qamar SA, Chen Z, Mengiste T: Arabidopsis WRKY33 transcription factor is required for resistance to necrotrophic fungal pathogens. Plant J 2006, 48(4):592-605.

71. Lin R, Zhao W, Meng X, Wang M, Peng Y: Rice gene OsNAC19 encodes a novel NAC-domain transcription factor and responds to infection by Magnaporthe grisea. Plant Sci 2007, 172(1):120-130.

72. Xia N, Zhang G, Liu XY, Deng L, Cai GL, Zhang Y, Wang XJ, Zhao J, Huang LL, Kang ZS: Characterization of a novel wheat NAC transcription factor gene involved in defense response against stripe rust pathogen infection and abiotic stresses. Mol Biol Rep 2010, 37(8):3703-3712.

73. Wang H, Jiang J, Chen S, Qi X, Peng H, Li P, Song A, Guan Z, Fang W, Liao Y, et al: Next-generation sequencing of the chrysanthemum nankingense (Asteraceae) transcriptome permits large-scale unigene assembly and SSR marker discovery. PLoS One 2013, 8(4):e62293.

74. Li R, Yu C, Li Y, Lam TW, Yiu SM, Kristiansen K, Wang J: SOAP2: an improved ultrafast tool for short read alignment. Bioinformatics 2009, 25(15):1966-1967.

75. Rozen S, Skaletsky H: Primer3 on the WWW for general users and for biologist programmers. Methods Mol Biol 2000, 132:365-386.

76. Song A, Lou W, Jiang J, Chen S, Sun Z, Guan Z, Fang W, Teng N, Chen F: An isoform of eukaryotic initiation factor $4 \mathrm{E}$ from Chrysanthemum morifolium Interacts with chrysanthemum virus $B$ coat protein. PLOS One 2013, 8(3):e57229.

doi:10.1186/1471-2164-15-9

Cite this article as: Li et al:: RNA-Seq derived identification of differential transcription in the chrysanthemum leaf following inoculation with Alternaria tenuissima. BMC Genomics 2014 15:9.

\section{Submit your next manuscript to BioMed Central and take full advantage of:}

- Convenient online submission

- Thorough peer review

- No space constraints or color figure charges

- Immediate publication on acceptance

- Inclusion in PubMed, CAS, Scopus and Google Scholar

- Research which is freely available for redistribution 